\title{
Infant feeding practices and prevalence of obesity in eight European countries - the IDEFICS study
}

\author{
Monica Hunsberger ${ }^{1}$ * , Anne Lanfer ${ }^{2}$, Anna Reeske ${ }^{2}$, Toomas Veidebaum³ \\ Paola Russo ${ }^{4}$, Charalampos Hadjigeorgiou ${ }^{5}$, Luis A Moreno ${ }^{6}$, Dénes Molnar ${ }^{7}$, \\ Stefaan De Henauw ${ }^{8,9}$, Lauren Lissner ${ }^{1}$ and Gabriele Eiben ${ }^{1}$ \\ 'Public Health Epidemiology Unit, Department of Public Health and Community Medicine, Sahlgrenska \\ Academy, University of Gothenburg, PO Box 454 SE-405 30, Gothenburg, Sweden: ${ }^{2}$ Bremen Institute for \\ Prevention Research and Social Medicine, Bremen, Germany: ${ }^{3}$ National Institute for Health Development, \\ Tallinn, Estonia: ${ }^{4}$ Institute for Food Sciences, Unit of Epidemiology and Population Genetics, National Research \\ Council, Avellino, Italy: ${ }^{5}$ Research and Education Institute of Child Health, Strovolos, Cyprus: ${ }^{6}$ Growth, Exercise, \\ Nutrition and Development (GENUD) Research Group, University of Zaragoza, Zaragoza, Spain: ${ }^{7}$ Department \\ of Pediatrics, Medical Faculty, University of Pécs, Budapest, Hungary: ${ }^{8}$ Department of Public Health, Ghent \\ University, Ghent, Belgium: 'University College Ghent, Department of Nutrition and Dietetics, Faculty of Health \\ Care 'Vesalius', Ghent, Belgium
}

Submitted 12 January 2012: Final revision received 8 June 2012: Accepted 16 July 2012: First published online 24 August 2012

\begin{abstract}
Objective: To assess the association between exclusive breast-feeding and childhood overweight.

Design: Cross-sectional data are from the baseline survey of the longitudinal cohort study IDEFICS. Exclusive rather than partial breast-feeding is the focus of the study due to the theoretical relationship between exclusive breast-feeding and development of dietary self-regulation. Children's measured heights and weights were used to calculate weight status, while waist-to-height ratio (WtHR) and skinfold measures were examined as alternative indicators of adiposity and fat patterning.

Setting: Examination centres in eight European countries (Italy, Estonia, Cyprus, Belgium, Sweden, Hungary, Germany and Spain).

Subjects: The analysis included 14726 children aged 2-9 years for whom early feeding practices were reported by parents in standardized questionnaires.

Results: After controlling for education, income and other potential confounders, breast-feeding exclusively for 4-6 months was protective of overweight (including obesity) when compared with children never exclusively breast-fed $(\mathrm{OR}=0.73 ; 95 \% \mathrm{CI} 0.63,0 \cdot 85)$ across all measures of overweight. Exclusively breast-feeding for 6 months offered slightly more protection than for 4 and 5 months combined $(\mathrm{OR}=0 \cdot 71 ; 95 \%$ CI $0 \cdot 58,0 \cdot 85)$. The associations could not be explained by socio-economic characteristics or maternal overweight.

Conclusions: This multi-country investigation indicated that exclusive breastfeeding for 4-6 months may confer protection against overweight in addition to other known benefits. There was no demonstrated benefit of exclusive breastfeeding for more than 6 months or combination feeding for any duration across all measures of overweight examined.
\end{abstract}

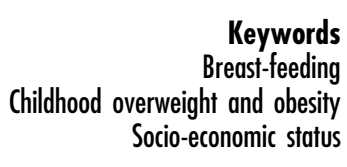

Exposure to breast-feeding decreases children's risk of gastroenteritis, lower respiratory tract infection, diabetes, sudden infant death syndrome and necrotizing enterocolitis $^{(1-3)}$. In addition, breast-feeding is widely believed to protect against overweight and obesity ${ }^{(1)}$. However, a number of studies have examined early nutrition and obesity with conflicting results. Differences in findings have been suggested to be due to a lack of control for confounding variables, small sample size, socio-economic status and other differences such as children's age at the time of measurement and family structure ${ }^{(4)}$. Some studies have reported a positive, dose-dependent association between breast-feeding and weight status ${ }^{(5-7)}$ while others have reported a non-linear positive response ${ }^{(8-10)}$. Conversely, other studies have demonstrated little or no protective association between breast-feeding and overweight $^{(11-14)}$. A longitudinal study of infant feeding and obesity found that exclusive breast-feeding was not 
related to being overweight or obese during adult life ${ }^{(15)}$, as did a systematic analysis conducted by the $\mathrm{WHO}^{(16)}$ and a systematic review of the literature which showed after adjustment for maternal overweight that the effect of breast-feeding was eliminated ${ }^{(17)}$. It has been suggested that breast-feeding alone does not protect children from overweight, but rather other healthy lifestyle habits or other social advantages of mothers who chose to breastfeed $^{(4)}$. While the relationship between breast-feeding and obesity has not been fully elucidated, it is recommended by the $\mathrm{WHO}^{(18)}$ and a Cochrane review ${ }^{(19)}$ that children are exclusively breast-fed for 6 months due to other known benefits; this is supported by the Committee on Nutrition of the European Society for Paediatric Gastroenterology, Hepatology and Nutrition (ESPGHAN), which recommends children be exclusively breast-fed for about 6 months $^{(1)}$.

In the present paper we examine whether exclusive breast-feeding, reported retrospectively on parental assessments, protects from childhood overweight in a sample of 14726 young children from eight European countries after controlling for mother's education, maternal overweight including obesity, household income, having foreign-born parents, family structure, child's birth weight, tobacco exposure, child's age and gender and survey country. The study will assist in elucidating the role of exclusive breast-feeding in protecting children from overweight and also if there is a particular duration of exclusive breast-feeding that appears to be most beneficial.

\section{Methods}

\section{Study sample}

IDEFICS (Identification and prevention of Dietary- and lifestyle-induced health EFfects In Children and infantS) is a multicentre European study involving eight countries. Community-based survey centres in each of the participating countries collected information when children were aged 2-9 years. The children were enrolled in the baseline survey from September 2007 until June 2008 at survey centres in Italy, Estonia, Cyprus, Belgium, Sweden, Hungary, Germany and Spain. The survey centres cannot be considered country representative. In total, over 16000 children participated in IDEFICS $^{(20)}$. From the IDEFICS population, children were included in the present study if their exposure to exclusive breast-feeding could be defined. After exclusions, the total sample size in the present study was 14726 with sample sizes across countries ranging from 1399 in Spain to 2431 in Hungary. Detailed information about the IDEFICS survey protocol has been published previously ${ }^{(20)}$.

\section{Etbical approval}

All applicable institutional and governmental regulations pertaining to the ethical use of human volunteers were followed during the research. All survey centres obtained ethics approval from their respective authority. Participants were not subjected to any study procedure before both the children and their parents gave their consent for examination and collection of samples and subsequent analysis and storage of personal data and collected samples. Parents or legal guardians provided written informed consent for their children, while the children gave oral consent. The participating children and their parents could consent to single components of the study while refraining from others.

\section{Feeding duration}

Exclusive breast-feeding duration was calculated from several variables reported in the parental questionnaire. Retrospective reporting of feeding practices gives reportedly good accuracy despite recalling over long periods of time ${ }^{(21-23)}$. Parents were asked to identify when they began and when they concluded the following feeding modalities: exclusive breast-feeding, combination feeding, formula feeding, and other feeding including cereals, vegetables, fruit, meat and cows' milk. In addition, parents were asked when the household diet was fully integrated into their child's diet which would indicate the child is consuming meals with the family. Exclusive breast-feeding means that breast milk is the only source of nutrition for the child and was calculated as the minimum of the stated end of exclusive breastfeeding or the beginning of the introduction to any other food or formula according to the parental questionnaire. In cases when exclusive breast-feeding overlapped with another type of feeding, exclusive breast-feeding was considered to end at the time when any other form of nutrition was introduced. Participants were excluded on the following bases: if no information on the type or timing of feeding was provided (1175 cases); if the stated end of exclusive breast-feeding was earlier than the start (one case); if exclusive breast-feeding was said to start in the second month of life or later (forty-four cases); if there was an indicated end of exclusive breast-feeding but no start of any other feeding was reported although the parent indicated yes to the start of other foods (eight cases); if there was no indicated end to exclusive breast-feeding and no indicated start of other foods (119 cases); and if exclusive breast-feeding for more than 12 months was indicated with no conflicting start of other foods (thirty-eight cases). Exclusive breast-feeding was then categorized into the following: never exclusively breast-fed, breast-fed exclusively for 1-3 months, breast-fed exclusively for 4-6 months and breast-fed exclusively for 7-12 months. Breast-feeding was reported in whole months and further categorized into categories: 1-3 months (including those beginning at birth), 4-6 months and 7-12 months.

\section{Antbropometry}

Anthropometric measurements were taken according to standardized operating procedures at all survey centre sites ${ }^{(24,25)}$. Body height without shoes was measured to 
the nearest $0 \cdot 1 \mathrm{~cm}$ by trained staff using a portable Seca 225 stadiometer (KWS Medical Supplies LLC, North Bend, WA, USA). Weight was measured by means of an adapted version of the Tanita BC 420 SMA electronic scale (Tanita Europe BV, Amsterdam, The Netherlands). BMI was calculated and categorized according to the criteria of the International Obesity Taskforce ${ }^{(26)}$. A continuous BMI $Z$-score was calculated and BMI was further dichotomized for analysis into 'overweight and obese' and 'normal and underweight'(26). Waist circumference was measured with the child standing upright, abdomen relaxed, arms at the sides and the feet together. The measure was taken at the midpoint between the top of the iliac crest and the lower coastal border or tenth rib. Skinfold thickness was measured at two sites, the triceps and subscapula, using a Holtain Skinfold Calliper (Holtain Ltd, Crosswell, UK) with the child in a standing position. All measurements were taken two times on the right side of the body. The two triceps measures and two subscapular measures were then averaged. Percentage body fat from skinfold measures was calculated using the equations developed by Slaughter et al. ${ }^{(27)}$; for boys, \% body fat $=0.783 \times($ sum of triceps and subscapular skinfolds) $-1 \cdot 7$; and for girls, $\%$ body fat $=0.546 \times($ sum of triceps and subscapular skinfolds) $+9 \cdot 7$. Waist-to-height ratio (WtHR) was also calculated for further assessment of adiposity ${ }^{(28)}$.

\section{Demographic characteristics and socio-economic variables}

Demographics and socio-economic variables were assessed from a standardized parental questionnaire. Children were examined in two age groups, 2 to $<6$ years of age and 6 to 9 years of age (or pre-school age and school age). Child's birth weight was categorized as low $(<2500 \mathrm{~g})$, normal or high $(\geq 4500 \mathrm{~g})$. Maternal overweight was dichotomized as normal (BMI $<25 \mathrm{~kg} / \mathrm{m}^{2}$ ) or overweight including obesity $\left(\mathrm{BMI} \geq 25 \mathrm{~kg} / \mathrm{m}^{2}\right)$. Socioeconomic status surrogates included maternal education, maternal tobacco use during pregnancy, household income, foreign-born parent(s) and family structure. To facilitate cross-country comparisons the educational level was categorized according to the International Standard Classification of Education (ISCED) into high, medium and low, where the original ISCED levels 0,1 and $2=$ low, 3 and $4=$ medium and $\geq 5=$ high educational attainment ${ }^{(29)}$. Maternal tobacco use of any kind (cigarettes or smokeless tobacco) was obtained from the parental questionnaire and depicted as 'never used tobacco' or 'used tobacco during pregnancy'. Household income was standardized across countries by considering the median income and poverty line equivalent for a single parent with one child in each country. Foreign-born parents were identified by two questions on the parental questionnaire, mother's birthplace and father's birthplace. Foreign-born parent represents one or both parents immigrating to the survey country. Family structure was characterized as single parent $v$. two parents. Finally, we controlled for differences by country of the survey centre.

\section{Statistical analysis}

Using multivariate logistic regression, we analysed the relationship between overweight and exclusive breast-feeding. We examined duration of exclusive breast-feeding in three categories (1-3 months, 4-6 months and 7-12 months) with never exclusively breast-fed as the referent category. To further assess the relationship between overweight and breastfeeding we repeated our multivariate analyses with two other indicators of overweight: WtHR dichotomized $(<0.5$ or $\geq 0.5$ ) in a logistic regression model and percentage body fat from skinfolds in a generalized linear model. In the multivariate models, we included covariates based on prior studies and known confounders. The criterion for statistical significance was $P \leq 0 \cdot 05$. All statistical analyses were performed using the statistical software package StataSE $8 \cdot 0$.

\section{Results}

Characteristics by survey centre are shown in Table 1 . The sample population had a $19.4 \%$ prevalence of overweight ranging from a high of $42 \cdot 3 \%$ in Italy to a low of $8.3 \%$ in Belgium at baseline data collection. The sample ranged in age from 2 to 9 years with a mean age of 6 years, forming two age groups of similar size: pre-school age ( 2 to $<6$ years) and school age ( 6 to 9 years). Of the sample population, $51 \cdot 7 \%$ were boys. Less than $19 \%$ of the sample was never exclusively breast-fed, with across survey country differences ranging from a high percentage of never breast-fed in Belgium (46.1\%) to a low percentage in Estonia (9.9\%; Table 1). The mean duration of exclusive breast-feeding was $3 \cdot 2$ months across all survey centres. The longest mean duration of exclusive breast-feeding was reported in Hungary (3.9 months) and the shortest in Belgium ( 1.7 months). The majority of children had a normal birth weight. A large percentage of mothers had low education at the German survey centre and there were many highly educated mothers at the Swedish survey centre. When the highest education in the household was examined a similar pattern emerged. The percentage of children with overweight mothers was lowest in Estonia $(24.6 \%)$ and highest in Germany (41.9\%). Approximately $15 \%$ of the children had at least one foreign-born parent; the greatest percentage was found in the German sample (32.9\%) and the lowest in the Hungarian sample $(4 \cdot 0 \%)$. The majority of families comprised two-parent households $(84 \cdot 6 \%)$. The Italian sample had the largest percentage of single-parent families (29.3\%) and the Swedish sample the lowest (5.2\%). Mean income, presented on a scale of 1 to 9 , averaged $5 \cdot 3$ across the survey centres with the highest score $(6 \cdot 9)$ found in Estonia and the lowest score $(3 \cdot 0)$ in Italy. Fourteen per cent of women reported using tobacco during their pregnancy. 
Table 1 Characteristics of the study population and distribution of covariates by country*: children aged 2 to 9 years $(n 14726)$ from eight European countries, IDEFICS study

\begin{tabular}{|c|c|c|c|c|c|c|c|c|c|c|c|c|c|c|c|c|c|c|}
\hline \multirow[b]{2}{*}{ Variable } & \multicolumn{2}{|c|}{$\begin{array}{c}\text { Italy } \\
\text { (n 2088) }\end{array}$} & \multicolumn{2}{|c|}{$\begin{array}{l}\text { Estonia } \\
\text { ( } n \text { 1577) }\end{array}$} & \multicolumn{2}{|c|}{$\begin{array}{l}\text { Cyprus } \\
\text { (n 1927) }\end{array}$} & \multicolumn{2}{|c|}{$\begin{array}{l}\text { Belgium } \\
(n \text { 1772) }\end{array}$} & \multicolumn{2}{|c|}{$\begin{array}{l}\text { Sweden } \\
\text { (n 1708) }\end{array}$} & \multicolumn{2}{|c|}{$\begin{array}{l}\text { Germany } \\
(n \text { 1824) }\end{array}$} & \multicolumn{2}{|c|}{$\begin{array}{l}\text { Hungary } \\
(n 2431)\end{array}$} & \multicolumn{2}{|c|}{$\begin{array}{l}\text { Spain } \\
\text { (n 1399) }\end{array}$} & \multicolumn{2}{|c|}{$\begin{array}{c}\text { All } \\
(n 14 \text { 726) }\end{array}$} \\
\hline & Mean & SD & Mean & SD & Mean & SD & Mean & SD & Mean & SD & Mean & SD & Mean & SD & Mean & SD & Mean & SD \\
\hline $\begin{array}{l}\text { Exclusive breast-feeding (months), mean \& SD } \\
\text { Exclusive breast-feeding (months), median } \\
\text { Breast-feeding category (\%) }\end{array}$ & \multicolumn{2}{|c|}{4} & \multicolumn{2}{|c|}{4} & \multicolumn{2}{|c|}{1} & \multicolumn{2}{|c|}{1} & \multicolumn{2}{|c|}{4} & \multicolumn{2}{|c|}{3} & \multicolumn{2}{|c|}{4} & \multicolumn{2}{|c|}{4} & $3 \cdot 1$ & $2 \cdot 4$ \\
\hline Never exclusively breast-fed & \multicolumn{2}{|c|}{$15 \cdot 0$} & \multicolumn{2}{|c|}{$9 \cdot 9$} & \multicolumn{2}{|c|}{$18 \cdot 8$} & \multicolumn{2}{|c|}{$46 \cdot 1$} & \multicolumn{2}{|c|}{$14 \cdot 7$} & \multicolumn{2}{|c|}{$12 \cdot 3$} & 11 & & 23 & & & 6 \\
\hline $1-3$ months & 31 & & & & 57 & & & & 18 & & & & 31 & & 23 & & 34 & 4 \\
\hline 4-6 months & 47 & & & & & & & & 65 & & & & 49 & & 49 & & 42 & 8 \\
\hline 7-12 months & & & & & & & & & & & & & & 2 & & 5 & & 2 \\
\hline Overweight (\%) & 42 & & & & 23 & & & & 10 & & & & 16 & & 20 & & 19 & \\
\hline WHtR, mean \& SD & 0.49 & $0 \cdot 0$ & 0.46 & 0.0 & 0.48 & 0.0 & 0.46 & 0.0 & 0.46 & $0 \cdot 0$ & 0.45 & 0.0 & 0.46 & 0.0 & 0.47 & 0.0 & 0.47 & 0.1 \\
\hline$\%$ Body fatt, mean \& SD & $18 \cdot 7$ & $0 \cdot 19$ & $15 \cdot 9$ & $0 \cdot 16$ & $15 \cdot 6$ & $0 \cdot 15$ & $14 \cdot 7$ & $0 \cdot 14$ & $14 \cdot 6$ & $0 \cdot 14$ & $16 \cdot 3$ & $0 \cdot 15$ & $15 \cdot 6$ & $0 \cdot 14$ & $16 \cdot 1$ & $0 \cdot 20$ & $16 \cdot 0$ & $6 \cdot 70$ \\
\hline Age (years), mean \& SD & $6 \cdot 1$ & $0 \cdot 0$ & $5 \cdot 8$ & $0 \cdot 1$ & $6 \cdot 1$ & $0 \cdot 0$ & $5 \cdot 6$ & 0.0 & $5 \cdot 7$ & $0 \cdot 1$ & $6 \cdot 1$ & $0 \cdot 0$ & $6 \cdot 3$ & $0 \cdot 0$ & $5 \cdot 7$ & $0 \cdot 0$ & $6 \cdot 0$ & $1 \cdot 8$ \\
\hline $2-<6$ years $(\%)$ & 43 & & & & 40 & & & & 51 & & & & 41 & & 47 & & 46 & 3 \\
\hline Boys (\%) & 52 & & & & & & & & 51 & & & & 50 & & 51 & & 51 & 7 \\
\hline Birth weightł (\%) & & & & & & & & & & & & & & & & & & \\
\hline High & & & & & & & & & & & & & & 5 & & 0 & & 0 \\
\hline Normal & 91 & & & & & & & & 91 & & & & 92 & & 89 & & 91 & \\
\hline Low & & & & & & & & & & & & & & 2 & & 2 & & 0 \\
\hline Maternal education§ (\%) & & & & & & & & & & & & & & & & & & \\
\hline High & 13 & & & & & & & & 59 & & & & 36 & & 44 & & 30 & \\
\hline Medium & 55 & & & & & & & & 34 & & & & 58 & & 40 & & 51 & \\
\hline Low & 30 & & & & & & & & & & & & & 6 & 15 & & 17 & \\
\hline Highest household education\| (\%) & & & & & & & & & & & & & & & & & & \\
\hline High & 18 & & & & 57 & & & & 69 & & & & 43 & & 51 & & 39 & \\
\hline Medium & 60 & & & & & & & & 28 & & & & 53 & & 39 & & 50 & \\
\hline Low & 20 & & & & & & & & & & & & & 9 & & 1 & 10 & \\
\hline Foreign-born parent $\uparrow(\%)$ & 17 & & & & $2 s$ & & & & 17 & & & & & 0 & 10 & & 15 & \\
\hline Maternal overweight* ${ }^{\star \star}(\%)$ & 39 & & & & $2 \varepsilon$ & & & & 31 & & & & 32 & & 25 & & 32 & \\
\hline Income scorett, mean \& SD & $3 \cdot 0$ & 0.04 & $6 \cdot 9$ & 0.06 & $4 \cdot 1$ & 0.08 & $5 \cdot 8$ & 0.05 & $6 \cdot 4$ & $0 \cdot 0$ & $4 \cdot 2$ & $0 \cdot 10$ & $5 \cdot 8$ & 0.05 & $6 \cdot 2$ & 0.05 & $5 \cdot 3$ & $2 \cdot 40$ \\
\hline Family structure, two-parentł‡ (\%) & 70 & & & & & & & & 94 & & & & 84 & & 97 & & 84 & 6 \\
\hline Tobacco use during pregnancy $\S(\%)$ & 12 & & & & & & & & 7 & & & & 10 & & 28 & & 14 & 3 \\
\hline
\end{tabular}

WtHR, waist-to-height ratio; ISCED, International Standard Classification of Education:

${ }^{*}$ Number of participants with breast-feeding variables, BMI, gender, age: totals vary slightly by analysis.

tCalculated using the Slaughter equation.

†Birth weight: low $=\leq 2500 \mathrm{~g}$; normal $=>2500$ to $<4500 \mathrm{~g}$; high $=\geq 4500 \mathrm{~g}$

\$Maternal education $=$ ISCED categories grouped into low, medium or high education by international classification.

$\|$ Household education = ISCED categories low, medium or high education by international classification of the highest education obtained in the household.

IForeign-born parent $=$ one or more parents migrated to study country but were born abroad.

${ }^{*}$ Maternal overweight $=\mathrm{BMl} \geq 25 \mathrm{~kg} / \mathrm{m}^{2}$

t+Income score $=$ total household income standardized to countries based on median income and poverty line equivalent for a single parent with one child on a 1-9 point scale.

t\#Family structure = single- or two-parent household.

$\S \S$ Tobacco use = using any tobacco during pregnancy. 
Table 2 Overweight and exclusive breast-feeding exposure: children aged 2 to 9 years $(n 14726)$ from eight European countries, IDEFICS study

\begin{tabular}{|c|c|c|}
\hline & OR & $95 \% \mathrm{Cl}$ \\
\hline \multicolumn{3}{|c|}{ Model 1: Breast-fed exclusively and overweight* } \\
\hline Never exclusively breast-fed & $1 \cdot 00$ & Ref. \\
\hline $1-3$ months & 0.90 & $0.79,1 \cdot 01$ \\
\hline $4-6$ month & 0.72 & $0.64,0.81$ \\
\hline $7-12$ months & 0.92 & $0 \cdot 74,1 \cdot 15$ \\
\hline \multicolumn{3}{|c|}{ Model 2: Model 1+demographic characteristics (child's } \\
\hline \multicolumn{3}{|c|}{ age, sex and birth weight) } \\
\hline Never exclusively breast-fed & $1 \cdot 00$ & Ref. \\
\hline $1-3$ months & 0.85 & $0.75,0.96$ \\
\hline 4-6 months & 0.68 & $0.60,0.77$ \\
\hline $7-12$ months & $0 \cdot 86$ & $0.69,1.08$ \\
\hline \multicolumn{3}{|c|}{$\begin{array}{l}\text { Model } 3 \text {, fully adjusted model: Model } 2+\text { SES (income, } \\
\text { maternal education and overweight, family structure, } \\
\text { tobacco use, foreign-born parent)t } t\end{array}$} \\
\hline Never exclusively breast-fed & $1 \cdot 00$ & Ref. \\
\hline $1-3$ months & 0.87 & $0.74,1.00$ \\
\hline 4-6 months & $0 \cdot 77$ & $0.66,0.90$ \\
\hline $7-12$ months & 0.95 & $0.73,1.23$ \\
\hline
\end{tabular}

SES, socio-economic status; Ref., referent category.

${ }^{*}$ Adjusted for survey centre.

tFewer observations in Model 3.

The greatest tobacco use was reported in Spain $(28 \cdot 1 \%)$ and the lowest in Sweden $(7 \cdot 1 \%)$.

In unadjusted analyses, children exclusively breast-fed for 4-6 months had less overweight and obesity at age 2-9 years than the reference group $(P=0 \cdot 005)$. When adjusting only for survey country, exclusive breast-feeding for $4-6$ months remained protective of overweight (Table 2). After adjusting for child age, sex and birth weight, exclusive breast-feeding for both 1-3 months and 4-6 months was protective of overweight (Table 2). Our fully adjusted multivariate model additionally included household income, maternal education, maternal overweight and obesity, single- or two-parent family structure, the presence of one or more foreign-born parents and tobacco use during pregnancy. In this analysis, exclusive breast-feeding for 4-6 months remained protective of overweight showing an inverse J-shaped association, with both 1-3 months and 7-12 months failing to reach statistical significance (Table 2). We further examined exclusive breast-feeding for 4 and 5 months combined and exclusive breast-feeding for 6 months. Six months exclusive breast-feeding was slightly more protective of overweight. Figure 1 illustrates differences in overweight and the associations with exclusive breast-feeding for 4 and 5 months $(P=0 \cdot 010)$ and 6 months $(P=0 \cdot 000)$ by survey country while controlling for confounding variables. The logistic regression model and the generalized linear regression model (Table 3) demonstrated that WtHR and percentage body fat (assessed by skinfold measures and calculated with the Slaughter equation) agree with our logistic regression findings (Table 2) and support our use of BMI as a binary outcome representing overweight children. Overall breast-feeding did not reach statistical significance in some countries but the direction was consistently negative (Fig. 1).

\section{Discussion}

In the present study, the relationship between exposure to exclusive breast-feeding and body fatness in children has been examined with three distinct outcome measures. We have studied overweight using BMI and WtHR as binary outcomes as well as percentage body fat as a continuous outcome in a large, diverse population while controlling for confounding variables. A recent review noted that differences in findings may be due to investigating binary outcomes $v$. linear outcomes ${ }^{(30)}$; here we report consistent results using both binary and continuous measures of overweight.

Our results demonstrate that exclusive breast-feeding for 4-6 months is protective of childhood overweight. This finding is consistent with other studies that have concluded breast-feeding is protective against paediatric overweight $^{(6,8-10,31)}$. However, we did not find the dose-response relationship that has been previously reported $^{(6,31)}$ but instead found a reverse $\mathrm{J}$-shaped response. Although breast-feeding was consistently associated with lower rates of overweight in children across exclusive breast-feeding groups, only 4-6 months exclusive breast-feeding reached statistical significance in our fully adjusted model. This finding was consistent whether we examined overweight using BMI as a binary outcome or using two other unique measures of overweight. It seems that 1-3 months exclusive breast-feeding may not be long enough to offer protection from overweight. Likewise, a longer duration did not lead to increasing benefit. In the latter group, this may be due to the small number of women who identified exclusively breast-feeding beyond 6 months $(4 \cdot 2 \%)$ or may represent misclassification of when solids were introduced. 




Fig. 1 Risk of overweight in children exposed to exclusive breast-feeding for 4-6 months stratified by country, 4-6 months all survey centres, 4-5 months all survey centres and 6 months all survey centres, compared with never breast-fed referent. Values are odds ratios, with $95 \%$ confidence intervals represented by vertical bars. Fully adjusted model stratified by survey centre includes child's gender, age and birth weight, tobacco use during pregnancy, maternal education, maternal overweight/obesity, highest household education, foreign-born parent(s), household income and family structure. Children aged 2 to 9 years ( $n 14726$ ) from eight European countries, IDEFICS study

Table 3 Exclusive breast-feeding and association with two other indicators of childhood overweight: children aged 2 to 9 years ( $n 14726$ ) from eight European countries, IDEFICS study

\begin{tabular}{|c|c|c|}
\hline & OR & $95 \% \mathrm{Cl}$ \\
\hline \multicolumn{3}{|c|}{ Model 1: Breast-fed exclusively and WHtR $(<0.5 v . \geq 0.5)$, logistic regression } \\
\hline Never exclusively breast-fed & $1 \cdot 00$ & Ref. \\
\hline $1-3$ months & 0.91 & $0.80,1.05$ \\
\hline 4-6 months & $0 \cdot 83$ & $0.73,0.96$ \\
\hline $7-12$ months & $0 \cdot 86$ & $0 \cdot 66,1 \cdot 11$ \\
\hline \multicolumn{3}{|c|}{ Model 2: Breast-fed exclusively and \% body fat, linear regression } \\
\hline $1-3$ months & & $-0.50,0.063$ \\
\hline 4-6 months & & $-0.73,-0.19$ \\
\hline $7-12$ months & & $-0.46,0.55$ \\
\hline
\end{tabular}

WtHR, waist-to-height ratio; Ref. referent category.

Model outcome variables: WHtR calculated from measured values of waist and height at non-fasting examination and percentage body fat calculated with Slaughter equation using triceps and subscapular skinfold measures.

Each model fully adjusted for survey centre, child's gender, age, birth weight, tobacco use during pregnancy, mother's education, mother's weight, highest household education, foreign-born parent(s), household income, family structure.

Although we considered the introduction of any other food to be the end of exclusive breast-feeding, a small percentage did report exclusive breast-feeding beyond the 6-month period that is recommended by the WHO and other nutrition authorities ${ }^{(1,18,19,32)}$. Since the optimal duration of exclusive breast-feeding is controversial, we examined 4 and 5 months combined exclusive breastfeeding and 6 months exclusive breast-feeding. We found 6 months exclusive breast-feeding offered slightly more protection against overweight, supporting the $\mathrm{WHO}^{(18)}$ and Cochrane review ${ }^{(19)}$ recommendations. Additionally, we analysed the introduction to complementary foods for associations with overweight, and found no relationship (results not shown).
Our findings are important because we have examined a large population representing diverse cultural groups whereas many others have focused on single populations. Moreover, we were able to control for a number of important confounding factors not always considered in other papers, including several indicators of socio-economic status and social circumstances. In addition, anthropometrics were measured by study staff according to a standardized protocol rather than relying on parentalreported weights and heights. Finally, we report on exclusive breast-feeding while some previous studies have focused on any breast-feeding, combining exclusive and partial.

The distinction between exclusive and partial breastfeeding is important. One explanation for the protective 
role of breast-feeding against overweight is self-regulation. Fisher et al. propose that breast-feeding through the first year of life allows infants to respond to internal hunger cues as opposed to external hunger cues. This self-regulation may be important to future energy intake regulation $^{(33)}$. It has also been proposed that breastfeeding may exert influence on hormone levels, such as insulin, which may influence future obesity. In a study of 9-month-old infants, thirteen exclusively breast-fed and seven weaned within the first 3 months of life, prefeeding concentrations of regulatory peptides, including insulin, did not differ but postprandial responses were significantly smaller in breast-fed infants than in formulafed infants ${ }^{(34)}$. The timing of infancy weight gain is another issue that may impact future overweight. Singhal et $a l^{(35)}$ have demonstrated a causal link between rapid early weight gain and the future risk for obesity. Finally, breast-feeding compared with formula-feeding positively impacts the digestive tract, leading to immediate and long-term health effects. Research suggests that changes in intestinal and pancreatic function that occur postnatally are modulated by diet ${ }^{(36)}$. Formula-fed infants have induced intestinal hypertrophy and accelerated maturation of hydrolysis capacities and are generally found to have higher necrotizing enterocolitis and diarrhoea during early life ${ }^{(36)}$. In large part, these differences are likely due to differences in the composition of breast milk and formula. Breast milk is not static in nature, unlike formula, as the protein composition of breast milk changes over periods of lactation ${ }^{(36)}$. Protein in $\mathrm{g} / 100 \mathrm{ml}$ is lower in human milk than in cows' milk formulas of either low-protein or high-protein formulations ${ }^{(37)}$. For these reasons we looked at exposure to exclusive breastfeeding rather than partial. Further, in a supplemental analysis (not shown) examining combination feeding and childhood overweight we found no association examining the same three outcomes (BMI $Z$-score, WtHR and adiposity by skinfold measure).

Despite the aforementioned strengths, the current study does have limitations. First, it is difficult to accurately access the true exposure duration to exclusive breast-feeding. The study relied on parental recall of feeding practices that for some parents meant recalling feeding practices occurring as long as 8 years prior, as the IDEFICS children ranged in age from 2 to 9 years. However, in a study of repeatability of maternal report with IDEFICS participants, the postnatal questions such as exclusive breast-feeding had fair-to-good repeatability ${ }^{(38)}$. In addition, our findings may not be considered representative on the country level. Therefore, we cannot make conclusions about countries but can instead generalize only to the study populations. For example, the study population in Germany included a rather large percentage of foreign-born parents with approximately $33 \%$ of households having one or more parent born outside Germany. This may be contrasted with the German Statistics Office which reported a total immigrant population of $8.7 \%$ in December $2009^{(39)}$. This large immigrant population may partially explain why a high proportion of German mothers had low levels of education. However, from the opposing view one might see this diversity as a benefit since IDEFICS may have captured some of the most vulnerable populations. More importantly, the German study population showed the strongest association between exclusive breast-feeding for 4-6 months and lower overweight/ obesity.

These findings further highlight the need for public health policies that support exclusive breast-feeding. The ESPGHAN Committee on Nutrition recommends exclusive breast-feeding for about 6 months as a desirable goal and further supports societal standards that allow for maternity leave for at least 6 months $^{(1)}$. When postnatal leave opportunities are considered in the context of our findings, there are areas for improved public health policy. Total postnatal leave paid at $>70 \%$ of earnings, compared in months, varies dramatically by country $^{(39)}$. Hungary, Sweden, Germany and Estonia offer 13-24 months while Belgium, Spain, Cyprus and Italy offer $0-4$ months ${ }^{(40)}$. Differences in breast-feeding policies are likely to explain some of the differences in exclusive breast-feeding. For example, only $9.9 \%$ of Estonians reported never breast-feeding while $46 \%$ of Belgians reported never breast-feeding. Hungary, Germany and Sweden also have generous leave policies and here we found that $49 \cdot 5 \%$ of Hungarians, $37 \cdot 0 \%$ of Germans and $65 \cdot 1 \%$ of Swedes breast-fed exclusively for 4-6 months. However, one must note that while the policies in Italy and Spain are not as generous, still $47 \cdot 2 \%$ and $49.9 \%$ respectively managed to exclusively breastfeed for 4-6 months.

Even though overweight is multifactorial in nature and breast-feeding alone will not offer long-term protection, our findings support the recommendation to exclusively breast-feed children for 6 months. Breast-feeding policies that support women in the endeavour to exclusively breast-feed for 4-6 months, with 6 months being an optimal goal, may improve public health as many nations struggle to reduce childhood overweight prevalence.

\section{Acknowledgements}

The study was supported by the European Community within the 6th RTD Framework Program Contract No. 016181 (FOOD). None of the authors have a conflict of interest. M.H., L.L. and G.E. designed the research project. M.H. conducted the research, completed all analyses and had primary responsibility for all parts of the manuscript. L.L., G.E., A.L., A.R., T.V., P.R., C.H., L.A.M., D.M. and S.D.H. gave input on the content of the paper and read and approved the final manuscript. 


\section{References}

1. ESPGHAN Committee on Nutrition: Agostoni C, Braegger C, Decsi T et al. (2009) Breast-feeding: a commentary by the ESPGHAN Committee on Nutrition. J Pediatr Gastroenterol Nutr 49, 112-125.

2. Ladomenou F, Moschandreas J, Kafatos A et al. (2010) Protective effect of exclusive breastfeeding against infections during infancy: a prospective study. Arch Dis Child 95, 1004-1008.

3. McNiel ME, Labbok MH \& Abrahams SW (2010) What are the risks associated with formula feeding? A re-analysis and review. Birth 37, 50-58.

4. Centers for Disease Control and Prevention, Division of Nutrition and Physical Activity (2007) Does Breastfeeding Reduce the Risk of Pediatric Overweight? Research to Practice Series no. 4. Atlanta, GA: CDC.

5. Kramer MS (1981) Do breast-feeding and delayed introduction of solid foods protect against subsequent obesity? J Pediatr 98, 883-887.

6. Arenz S, Ruckerl R, Koletzko B et al. (2004) Breastfeeding and childhood obesity - systematic review. Int J Obes Relat Metab Disord 28, 1247-1256.

7. Harder T, Bergmann R, Kallischnigg G et al. (2005) Duration of breastfeeding and risk of overweight: a metaanalysis. Am J Epidemiol 162, 397-403.

8. von Kries R, Doletzko B, Sauerwald T et al. (1999) Breast feeding and obesity: cross sectional study. BMJ 319, 147-150.

9. Woo JG, Dolan LM, Morrow AL et al. (2008) Breastfeeding helps explain racial and socioeconomic status disparities in adolescent adiposity. Pediatrics 121, 458-465.

10. Gillman MW, Rifas-Shiman SL, Camargo CA et al. (2001) Risk of overweight among adolescents who were breastfed as infants. JAMA 285, 2461-2467.

11. Toschke AM, Martin RM, von Kries R et al. (2007) Infant feeding method and obesity: body mass index and dual-energy X-ray absorptiometry measurements at $9-10 \mathrm{y}$ of age from the Avon Longitudinal Study of Parents and Children (ALSPAC). Am J Clin Nutr $\mathbf{8 5}$, 1578-1585.

12. Seach KA, Dharmage SC, Lowe AJ et al. (2010) Delayed introduction of solid feeding reduces child overweight and obesity at 10 years. Int J Obes (Lond) 34, 1475-1479.

13. Huus K, Ludvigsson JF, Enskär K et al. (2008) Exclusive breastfeeding of Swedish children and its possible influence on the development of obesity: a prospective cohort study. BMC Pediatr 8, 42-47.

14. Kramer MS, Matush L, Vanilovich I et al. for the PROBIT Study Group (2007) Effects of prolonged and exclusive breastfeeding on child height, weight, adiposity, and blood pressure at age $6.5 \mathrm{y}$ : evidence from a large randomized trial. Am J Clin Nutr 86, 1717-1721.

15. Michels KB, Willett WC, Graubard BI et al. (2007) A longitudinal study of infant feeding and obesity throughout life course. Int J Obes (Lond) 31, 1078-1085.

16. Horta BL, Bahl R, Martines JC et al. (2007) Evidence of the Long-Term Effects of Breastfeeding. Systematic Reviews and Meta-Analyses. Geneva: WHO; available at http://whqlibdoc.who.int/publications/2007/9789241595230_eng.pdf

17. Owens CG, Martin RM, Whincup PH et al. (2005) The effect of breastfeeding on mean body mass index throughout life: a quantitative review of published and unpublished observational evidence. Am J Clin Nutr 82, 1298-1307.

18. World Health Organization (2011) Media Centre Statement 15 January 2011. Exclusive breastfeeding for six months best for babies everywhere. http://www.who.int/mediacentre/news/statements/2011/breastfeeding_20110115/en/ index.html\# (accessed June 2011).
19. Kramer MS \& Kakuma R (2009) Optimal duration of exclusive breastfeeding (review). Cochrane Database Syst Rev issue 1, CD003517.

20. Ahrens W, Bammann K, Siani A et al. (2011) The IDEFICS study: design, characteristics and participation in the baseline survey. Int J Obes (Lond) 35, Suppl. 1, S3-S15.

21. Launer LJ, Forman MR, Hundt GL et al. (1992) Maternal recall of infant feeding events is accurate. J Epidemiol Community Health 46, 203-206.

22. Promislow JHE, Gladen BC \& Sandler DP (2005) Maternal recall of breastfeeding duration by elderly women. $A m \mathrm{~J}$ Epidemiol 161, 289-296.

23. Li R, Scanlon KS \& Serdula MK (2005) The validity and reliability of maternal recall of breastfeeding practice. Nutr Rev 63, 103-110.

24. Bammann K, Peplies J, Sjöström M et al. (2006) Assessment of diet, physical activity and biological, social and environmental factors in a multi-centre European project on diet- and lifestyle-related disorders in children (IDEFICS). Public Health 14, 279-289.

25. Stomfai S, Ahrens W, Bammann $\mathrm{K}$ et al. on behalf of the IDEFICS Consortium (2011) Intra- and inter-observer reliability in anthropometric measurements in children. Int J Obes (Lond) 35, Suppl. 1, S45-S51.

26. Cole TJ, Bellizzi MC, Flegal KM et al. (2000) Establishing a standard definition for child overweight and obesity worldwide: international survey. BMJ 320, 1240-1243.

27. Slaughter MH, Lohman TG, Boileau RA et al. (1988) Skinfold equations for estimation of body fatness in children and youth. Hum Biol 60, 709-723.

28. Yan W, Bingxian H, Hua Y et al. (2007) Waist-to-height ratio is an accurate and easier index for evaluating obesity in children and adolescents. Obesity (Silver Spring) 15, 748-752.

29. United Nations Educational, Cultural and Scientific Organization (2006) International Standard Classification of Education ISCED 1997. Montreal: UNESCO Institute for Statistics; available at http://www.uis.unesco.org/TEMPLATE/pdf/isced/ISCED_A.pdf

30. Beyerlein A \& von Kries R (2011) Breastfeeding and body composition in children: will there ever be conclusive empirical evidence for a protective effect against overweight? Am J Clin Nutr 94, 6 Suppl., 1772S-1775S.

31. Grummer-Strawn LM \& Mei Z (2004) Does breastfeeding protect against pediatric overweight? Analysis of Longitudinal Data from the Centers for Disease Control and Prevention Pediatric Nutrition Surveillance System. Pediatrics 113, e81-e86.

32. Dewey K on behalf of the WHO Complementary Feeding Consortium (2001) Guiding Principles for Complementary Feeding of the Breastfed Child. Geneva: WHO.

33. Fisher JO, Birch LL, Smiciklas-Wright H et al. (2000) Breastfeeding through the first year predicts maternal control in feeding and subsequent toddler energy intakes. J Am Diet Assoc 100, 641-646.

34. Salmenperä L, Perheentupa J, Siimes MA et al. (1988) Effects of feeding regimen on blood glucose levels and plasma concentrations of pancreatic hormones and gut regulatory peptides at 9 months of age: comparison between infants fed with milk formula and infants exclusively breast-fed from birth. J Pediatr Gastroenterol Nutr 7, 651-656.

35. Singhal A, Kennedy K, Lanigan J et al. (2010) Nutrition in infancy and long-term risk of obesity: evidence from 2 randomized controlled trials. Am J Clin Nutr 92, $1133-1144$.

36. Huërou-Luron I, Blat S \& Bourdy G (2010) Breast v. formula-feeding: impacts on the digestive tract and immediate and long-term health effects. Nutr Res Rev 23, 23-36.

37. Socha P, Grote V, Gruszfeld D et al. for the European Childhood Obesity Trial Study Group (2011) Milk protein 
intake, the metabolic-endocrine response, and growth in infancy: data from a randomized clinical trial. Am J Clin Nutr 94, 6 Suppl., 1776S-1784S.

38. Herrmann D, Suling M, Reisch L et al. (2005) Repeatability of maternal report on prenatal, perinatal and early postnatal factors: findings from the IDEFICS parental questionnaire. Int J Obes (Lond) 35, Suppl. 1, S52-S60.
39. German Federal Population Statistics (2010) Foreign Immigrants. http://www.statistik-portal.de/Statistik-Portal/ en/en_jb01_jahrtab2.asp (accessed June 2011).

40. Wall K \& Deven F (2009) Family Policy in Council of Europe Member States. http://www.coe.int/t/dg3/ familypolicy/Source/Family_Policy_in_Council_of_Europe_ member_states_en.pdf (accessed June 2011). 